\title{
A concept of drive and control system of a novel device for people evacuating from large passenger ships
}

Czesław Dymarski, Prof.

Gdansk University of Technology

\section{ABSTRACT}

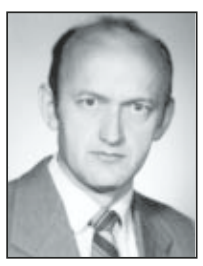

Year-after-year increasing number and size of sea-going passenger ships make it necessary to search for novel methods of evacuation of passengers from such large objects or to improve those which have been applied so far. This paper presents a concept of one of the original methods, in which, a.o., chain lifts have been applied to hold up life boats during voyage as well as to launch them in case of evacuation. Technical assumptions and requirements as well as schematic diagram of the hydraulic drive and control system of the lift, is presented.

Keywords: ship deck equipment; ship evacuating systems; life saving appliances systems;

hydraulic drive and control system

\section{USE OF THE ELABORATED CONCEPT OF THE DEVICE}

The presented concept of evacuation method of people from a large passenger ship was elaborated by this author for the passenger ship Queen Mary 2 in the frame of the European project SAFECRAFTS. This choice has been based on the fact that the ship has been so far one of the most modern and largest passenger ships intended for shipping on North Atlantic route.
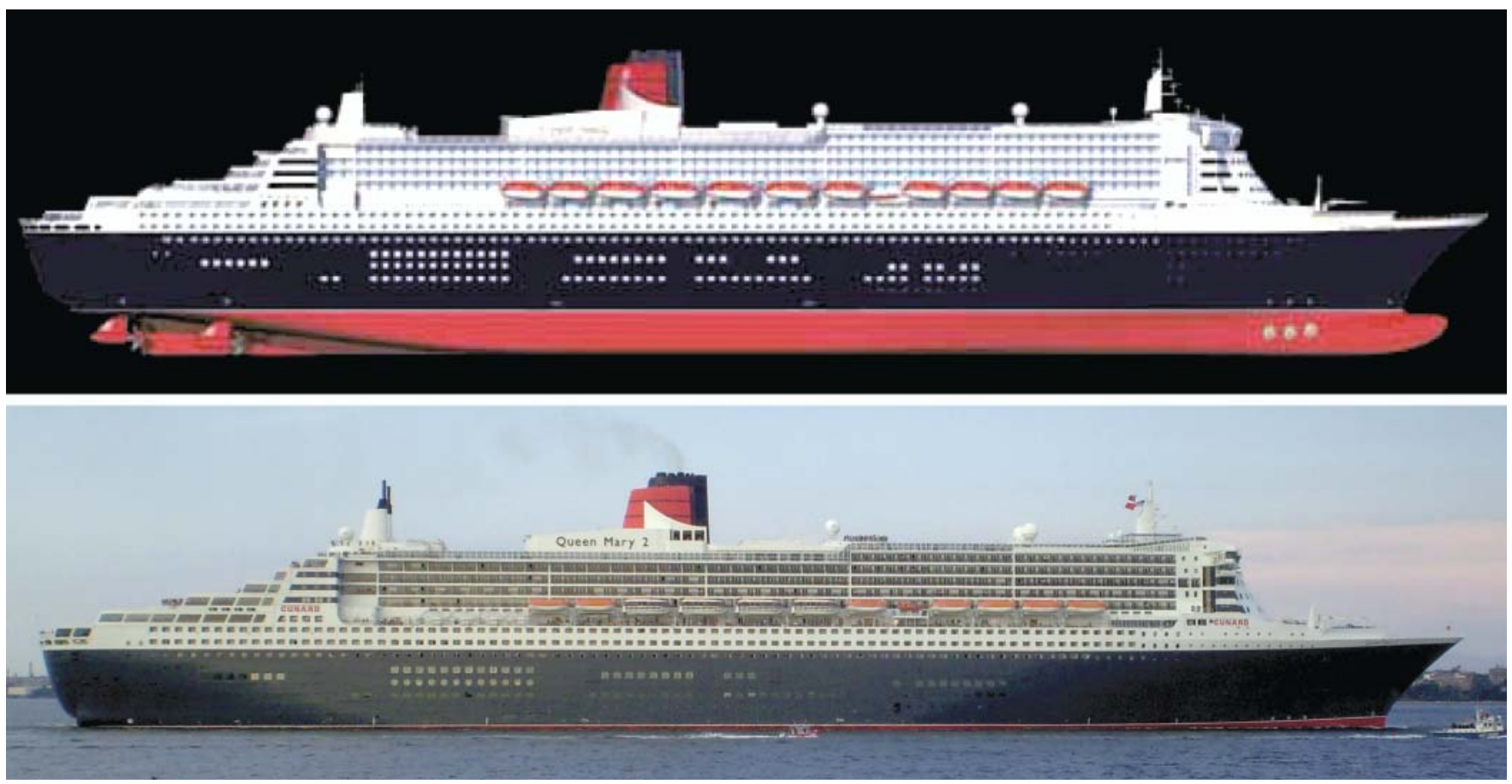

Fig. 1. The ship Queen Mary 2 with visible life boats placed on ship's side [7, 8] 
The main technical and operational parameters of the ship are as follows:

Length:

Breadth:

$345 \mathrm{~m}$

Draught:

$41 \mathrm{~m}$

$10 \mathrm{~m}$

Overall height (keel-chimney): $72 \mathrm{~m}$

Displacement:

$150000 \mathrm{t}$

Maximum speed:

$\sim 30$ knots

Power:

$115,4 \mathrm{MW}$

Drive:

4 pod propellers of $21,5 \mathrm{MW}$ power each, two of them azimuthal

Number of passengers and crew members:

$$
2620+1253=3873
$$

\section{GENERAL CONCEPT OF THE DEVICE}

The general concept of the evacuation device is presented in Fig. 2. It consists in location of life boats not on ship sides as until now, but aft in two (or more) casings placed symmetrically.
On each side of walls of the casing are located two chain lifts fitted with special suitably spaced catches on which life boats pointing aft are placed horizontally. In emergency, people embark on all the boats simultaneously through doors close to aft parts of the boats. In the same time the stern ramp opens gravitationally. After taking seats in the boats and closing the doors the releasing system of hooks keeping the boats is triggered remotely from the boats or a ship control post, and then the system of stabilized gravitational launching the boats is put in operation. The boats launched one by one, in the instant of getting support on the slipway rollers, are automatically released out of the chain lift catches and drive down the slipway and ramp into water. The presented device is equipped with a line hoisting winch located in the fore upper part of the slipway. It is intended for the hoisting of successive boats out of water, e.g. after tests of the device, through the ramp to the extreme fore position on the slipway, from which each boat is lifted up on the catches of the chain lift unit under operation. As a result of an analysis it was concluded that the particular units of the system, i.e. the chain lift, stern ramp as well as line hoisting winch should be driven hydraulically,

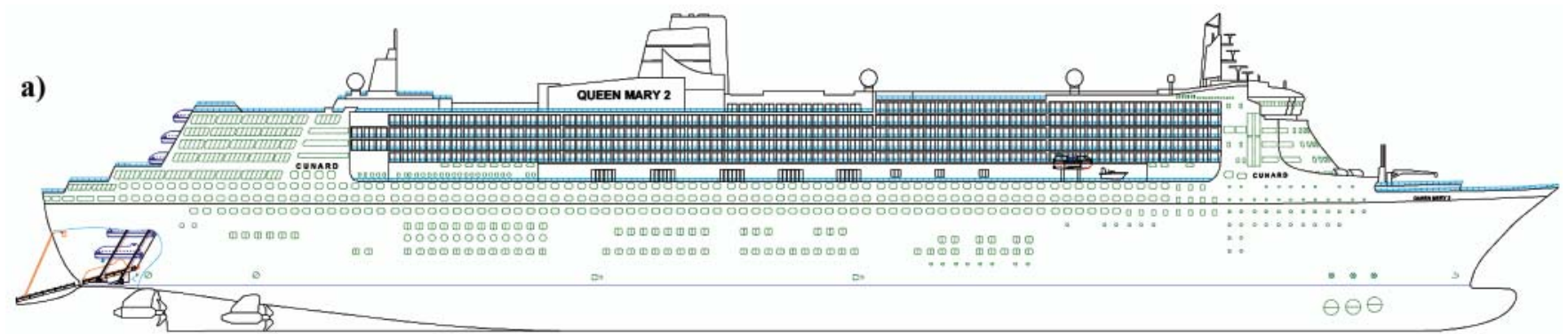

b)
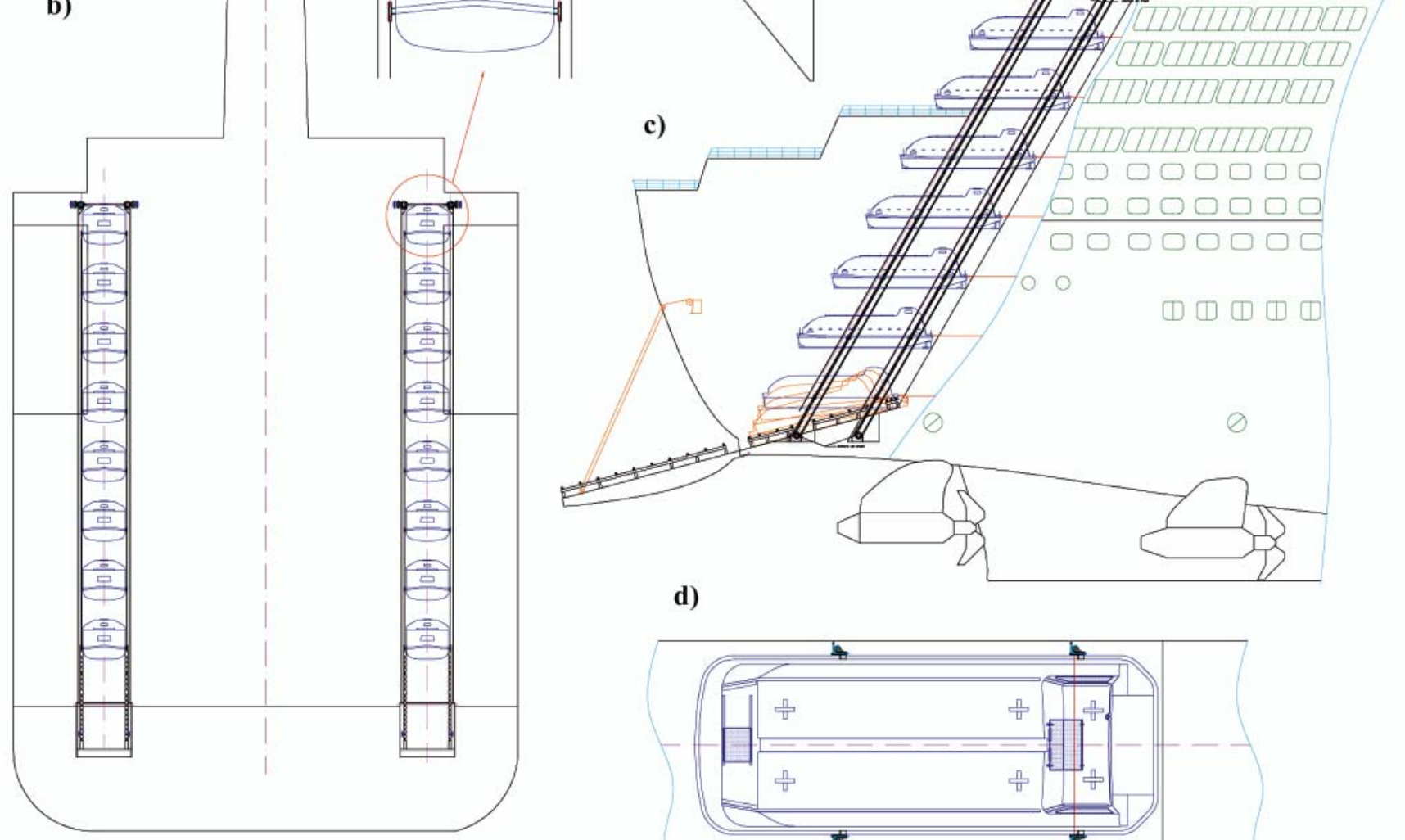

d)

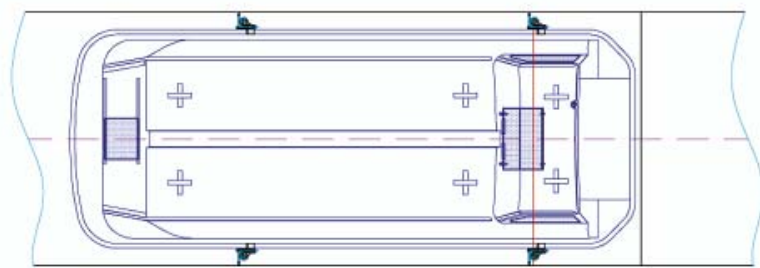

Fig. 2. General concept of the device for evacuation of people: $\boldsymbol{a}$ ) side view of the ship with the device installed on it; $\boldsymbol{b})$ aft view of the ship with visible elements of drive system; c) cross-section through the casing with chain lifts and life boats; d) top view of the life boat placed on the chain lift in the casing 
in view of expected large variable loading, small speeds and a necessary high precision of motion.

\section{DESCRIPTION OF OPERATIONAL PRINCIPLE OF THE EVACUATING SYSTEM}

As mentioned above, the designed evacuating system consists of two independent devices contained in special casings located aft, behind the profitable space of the ship. In each casing four chain lifts mechanically coupled to each other, two on each side wall, are placed. In the lower part of the casing the slipway fitted with rollers is located. The casing is open from aft. Only the lower aft part of the casing can be closed by means of a simple ramp fitted, at its inner side, with a frame with rollers; this way after opening the ramp the frame can serve as an extension of the slipway as far as under water level. To the chains of the lift the catches suitably spaced to support closed life boats, are fixed. During voyage the lift's drive is kept blocked mechanically. Also, the location of the life boats on the lift's catches is blocked by means of the so called slip hooks which are also equipped with a hydraulic release, apart from a typical mechanical release. Owing to this in the case of sinking the ship its life boats are able to free themselves automatically. In view of the shape and location of the casings, eight life boats per each casing are provided for the ship as large as the Queen Mary 2. Number of life boats is limited by ship's height [depth] as well as a required spacing between successive boats; the boats are rather large, of the capacity of 120 or 150 persons. The spacing between the boats is to be such as to prevent possible collisions during evacuation. Specificity of the presented concept consists in that it makes it possible to evacuate all people on board simultaneously and to remotely start launching operation also from inside of a life boat. The this - way triggered evacuation process will be continued automatically until the last boat is launched. When the first launched boat is already placed in the slipway and starts driving on the rollers in uniformly accelerated motion, the successive boat on the chain lift is approaching the preceding one. For this reason it is very important to keep an appropriate spacing between the boats.

A favourable feature of the solution in question is that persons embark the boat when it is stiffly connected with ship's hull. This way, in the presented solution, the problem of movement of the boat against the ship, that usually occurs in the case of embarking the boat hanging along ship side, was eliminated. Owing to this, people are not exposed to stress and fear which is a typical reaction to the sight of rough sea in the gap between the boat and ship side during embarkment on the boats launched in the traditional way by means of side boat davits. There are no impacts of the boat against ship side and in consequence no impact loads on the boat and passengers as well, which usually happen during lowering the life boats hanging on lines along side of the ship rolling in waves, especially in heavy weather conditions. In the discussed solution the process of lowering and launching the boats is fully controlled and free of any sudden accelerations and panting against water surface as it is in the case of evacuation systems based on free-fall lifeboats. Engine of the boat is started up during its going down along the slipway. As during launching the boat moves in opposite direction relative to the ship, therefore, being already in water, it continues the motion and sails away from the endangered ship. The above mentioned features are of special importance for older and handicapped persons for which both stress and sudden accelerations could be dangerous. Structure of the boats used in the presented solution contains some features of both free-fall boats and life boats lowered with the use of side davits. Like free-fall boats, they have specifically formed sides adjusted to going down on rollers. Because of their launching mode which causes much smaller dynamic loads they do not need to be as much resistant to loads as the free-fall boats. Their proportions are similar to those of free-fall boats, namely, they are more slender and longer than the side lifeboats. This makes it possible to save a part of expensive usable space of ship. The launching mode consists in lowering the boats at a controlled speed by using the chain mechanism. The motion takes place as a result of gravity forces and its speed is limited by means of a two-way flow controller installed in the hydraulic lift system, or a centrifugal brake. The boats are horizontally placed on the lift both during ship voyage and lowering process. In the lower part of the casing the boat, while settling on the rollers fastened to the frame inclined by $15^{\circ}$ against the deck level, releases itself from the chain lift. In the initial, fore part of the slipway three rollers are placed very close to each other to provide a greater comfort during the transient phase of evacuation when the boat changes its angular position. The boat travels its final path along the slipway inside the ship hull and next the stern ramp, developing uniformly accelerated motion and freely going down on rollers so as to enter the water at a relatively small slope angle. It highly moderates dynamics of its contact with water and lowers accelerations acting on the boat and people inside.

In the proposed solution a simple ramp was used. It consists of a main segment built of steel plating, a number of stiffeners and frames, which provide sufficient stiffness and strength of the ramp in heavy sea conditions. On the outer surface of the ramp there is a metal frame made of square cross-section pipes to which rollers are fixed so that after opening the ramp the structure serves as an extension of the slipways, along which the boats go down to water.

The drive of the ramp consists of a double-drum line hoisting winch and double pulley block system on both sides of the ramp. The motor of the winch is fitted with a blocking brake equipped with a hydraulic release. The lowering of the ramp is realized gravitationally at a speed stabilized and controlled by means of a two-way flow controller and centrifugal brake, if necessary. The drive and control system of the ramp is rather complex. It contains additional elements which serve to pull closer and block the ramp in the voyage position, and - in the case of a variant solution - units for automatic adjusting the angle of its opening depending on ship's draught and trim. As the system is multi-variant and complex the authors have resigned from publishing its description in detail in this paper.

The ramp together with the line hoisting winch located in the ship's hull just before the ramp constitutes a system for hoisting the boats out of water after evacuation trials. The boats are pulled one by one onto the ramp and further onto the slipway where they are placed on the chain lift catches and after that the lift is put into motion. In the instant when a boat is displaced upward the casing to a level assigned on the scale of boat arrangement, which is controlled by sensors, the chain lift is automatically stopped until a successive boat is taken out of water and placed on the catches, and then the mechanism is put in operation, the process is repeated again and again up to the last boat.

For driving the mutually coupled chain lifts, four winches fitted with double chain wheel and high-torque hydraulic motor equipped with blocking brake, hydraulic release and, if necessary,additional centrifugal brake, are used. Boat's lowering speed is stabilized and controlled by a two-way flow controller. A schematic diagram of the hydraulic drive 
and control system is presented in the next section. Fast and efficient evacuation of people from all decks of the ship is ensured by an appropriate form of staircases and a visual and acoustic system for directing the people to the life boats. The concept is based on that the doors leading from the staircases are located just opposite the entrances to the boats. Moreover, an emergency passage connecting successive levels, placed just behind the casing, is provided to facilitate people displacing in emergency. And, in this area anti-slipping materials are used to prevent people from slipping and falling down.

\section{HYDRAULIC DRIVE AND CONTROL SYSTEM FOR CHAIN LIFTS}

The hydraulic drive and control system for the chain lifts is presented below in Fig. 3.

The main task of the system in question is to ensure that all the boats with embarked people, placed on the chain lift, can be lowered with an appropriate, possibly constant speed in the conditions of no electric supply from ship's power plant. And, it was assumed that it should be possible to stop and start again the boat lowering operation from a post on board the ship. Moreover the system should be capable of hoisting all the boats without people but with full standard equipment. In the presented system the boat lowering operation will be performed gravitationally at switched-off electric motor (4). Pressure in the accumulator (7) should be checked before starting-up the operation. The accumulator is hydraulically connected (R) with the drive system of the stern ramp whose operation of opening, executed earlier, automatically triggers the accumulator charging. To be on the safe side, the small hand-pump (3) by which the accumulator can be charged, is added. The starting-up of the chain lifts with boats is executed by switching over the distributors (8) and (7) to the right, remotely - from the upper boat or locally - from the control post. This makes oil to flow from the accumulator (7) to the

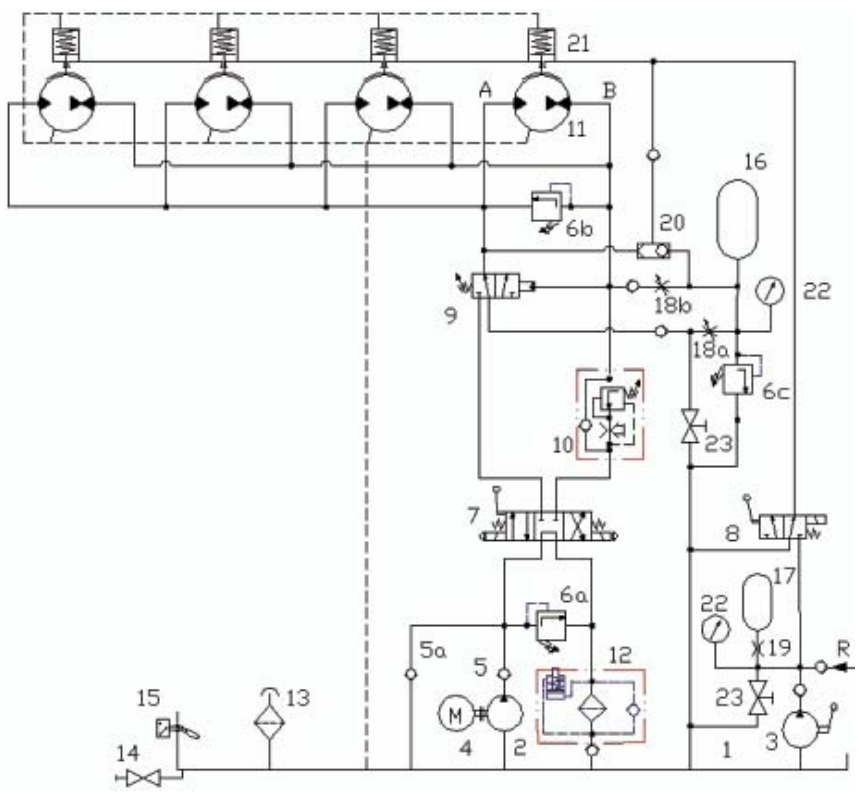

Fig. 3. Schematic diagram of the hydraulic drive and control system for the life-boat chain lift. Notation: 1), 13), 14) and 15) oil tank with equipment; 2) and 4) pump and electric motor; 3) hand-pump; 5) check valves; 6) overflow valve; 7) four-way three-position distributor;

8) and 9) three-way two-position distributors; 10) two-way flow controller;

11) hydraulic motors of constant absorbing capacity; 12) oil filter;

16) and 17) hydraulic-gas accumulators; 18) and 19) throttle valves; 20) pressure control valves; 21) hydraulic brake release; 22) manometers; 23) cut-off valves; $\boldsymbol{A}, \boldsymbol{B}$-stands for main circuit branches, $\boldsymbol{R}$ - stands for oil inflow from stern-ramp drive system hydraulic brake releases (21) causing a sudden rise of pressure in the right branch (B) of motor circuit due to external load. In consequence the distributor (9) is then switched over to the left making this way oil to flow from the tank (1) through the distributor (7) and (9) to the motors (11) due to their pumping work resulting from the load of the boats with people. Speed of the motion is stabilized by the two-way flow controller (10). In the first phase of the process the motion will be somewhat faster because of the high oil pressure dependent on the load as well as due to the fact that a part of the oil pressed from the branch pipe (B) is gradually drained from the branch (B) through the throttle valve (18b) to the accumulator (16). The accumulator is aimed at making the lowering motion fluent also during placing the last boat on the rollers and releasing it from the catches when the external load of the motors (11) is too low to overcome friction forces in the system and ensure their pumping work. When the oil pressure in the branch (B) drops down to its threshold level set by the spring of the distributor (9), it will be switched over to the position of connecting the accumulator (16) with the charging branch (A) of the motors (11), that will ensure continuous work of the chain lift.

\section{FEATURES OF THE SYSTEM}

The crucial features which characterize various aspects of the elaborated concept are the following:

1. Safety of the proposed evacuating system from the point of view of passengers:

- simple and safe access to life boats (appropriately formed staircases leading straight to boats, on every deck level a boat can be find),

- stiff connection of boat and gangway relative to the ship (there are no mutual displacements of boat and ship; rough sea is not visible during embarkation on boats),

- a relatively lower load exerted on people,

- a gentle acceleration effect to people inside the boat (neither panting of boat against ship side nor slamming against water occurs),

2. Safety and reliability of the system in question:

- easiness of simultaneous control of readiness of all boats (access openings or doors fitted with sight glasses are provided for in casing walls to make it possible to reach the boats,

- collision-free launching (the boats are placed on the chain mechanism supports, with keeping safe mutual distance so as to make the just launched boat going far away possible until the successive boat is in water),

- easy and safe launching the boats (the applied system of rollers located in the end part of the casing makes it possible to gently transfer the boats from the lowering mechanism onto the slipway equipped with rollers, due to which the boat is able to slide into water automatically)

- safe contact of boat with water (for the time of evacuation the slipway located in the end part of the casing, can be extended by the length of the ramp partly immersed in water, due to which the boat goes bows-on into water under a small entrance angle; its engine is started in advance on the slipway, and, the boat departs just after launching in the direction opposite to that of ship's motion),

- the system in question does not require any large number of operators nor special skill,

- the boat lowering process runs automatically under gravity forces, 
- the launching can be performed to water area behind the stern of the ship under motion, free of ice floats and possible contaminations, i.e. in the conditions that can not be ensured at the side of ship,

3. Quickness of evacuation:

- on average a shorter distance is to be covered by evacuating persons,

- simultaneous access to all boats from particular decks of ship,

- less confusion than during evacuation by using a boat system having side boat davits when all passengers gather on one and the same deck,

- a shorter evacuation process as all the boats are lowered simultaneously after starting up only one common driving system (the starting-up of the driving system which lowers the boats is preceded by the simultaneous lifting-up of all gangways and releasing the hooks (releases) of the mechanisms blocking the boats during ship voyage).

4. Technical merits:

- less number of mechanisms than in the case of side evacuation systems using side boat davits,

- a great simplicity of mechanisms, hence a higher reliability,

- low cost of devices.

5. Analysis of the applied boats:

- the boats applied in the proposed solution are of a smaller breadth and a little greater length than the side boats, and their form is rather similar to the free-fall boats,

- their structure is adjusted to going down on rollers,

- their strength is not required to be as big as that of freefall boats because dynamic loads applied to them are much smaller (comparable to loads exerted to classical boats launched by using side davits, or even smaller).

6. Possible automatic freeing the boats in case of sinking the ship:

- this is fully possible as the casing is open from the ship stern side, and only in its lower part there is the gravitationally openable ramp closed during voyage; the releasing system of ramp clamping devices is integrated with that of hooks keeping the boats in their voyage position as well as with the system for folding the gangways after embarkation of people on boats, which is automatically triggered by the hydrostatic release.

7. Procedure of hoisting the boats after evacuation trials and fastening the boats during voyage:

- the double-drum line-hoisting winch is so located in ship's hull that it does not interfere in ship's image and esthetic merits,

- the voyage position of boats on the chain lifts is blocked by slip hooks, like in the systems for free-fall boats.

8. Overall merits:

- the system simultaneously operates on all decks,

- the whole evacuation system occupies a relatively small area because the boats are placed one over the other,

- the location of the system is favourable because it does not occupy the expensive hotel space fitted with windows.
- more safe and comfortable operation of people embarking on boats,

- a smaller resistance of ship to motion,

- a more esthetic image of ship,

- during ship sinking the freeing of boats is fully possible.

9. Disadvantage:

- Possible blockage of even only one boat causes the chain lift stopping and necessessity of emptying the boat and next removing it off the chain lift by using a line hoist (not shown in the drawing) installed on both walls of the casing, and placing the boat onto the slipway fitted with rollers, that unfortunately will make the evacuation process longer. A more detailed description of the blocked boat removing system is rather extensive, hence it could be presented in a separate paper.

\section{BIBLIOGRAPHY}

1. Dymarski Cz., Dymarski P.: Shipboard life saving and rescue equipment $-R \& D$ projects (in Polish). Materials of $10^{\text {th }}$ International Scientific Technical Conference „, Safety at Sea and Marine Environment". $5^{\text {th }}$ Maritime Forum, Koszalin Kołobrzeg 2006, Ed. NOT, Koszalin 2006.

2. Dymarski Cz., Łubiński P.: Safe evacuation of people from ships - research performed in the frame of the European Research Project SAFECRAFTS (in Polish). Materials of $8^{\text {th }}$ Conference on Shipbuilding and Ocean Technology, „Development prospects of transport systems”, Międzyzdroje, June 2006. Publ. Szczecin University of Technology, Szczecin 2006

3. Dymarski Cz., Kraskowski M., Sperski M.: Investigation of motion of the lifeboat lowered from ship's deck. Polish Maritime Research. - Vol. 13, no. 3, 2006

4. Dymarski Cz., Dymarski P.: A system for evacuation of people from multi-deck ship, passenger ship in particular (in Polish). Patent application No. P 379355, dated 3 April 2006

5. Dymarski Cz., Łubiński P., Dymarski P.: Ramp and chain-liftlaunched lifeboats - radical concepts for evacuating cruise ships. Naval Architect, October 2006

6. Dymarski Cz.: A concept of drive and control system of a novel device for people evacuating from large passenger ship. Research and construction (in Polish). Materials of the Conf. on „Wytwarzanie i Eksploatacja Układów Hydraulicznych” CYLINDER 2009 (Production and Operation of Hydraulic Systems), Szczyrk, 23 $\div 25$ August 2009, Publ. Centrum Mechanizacji Górnictwa KOMAG.

7. Stareńczak P.: The Queen Mary 2 - a new queen of oceans (in Polish). Budownictwo Okrętowe, nr 1 (534), January 2004

8. http://www.marinetraffic.com/ais/pl/showallphotos. aspx?mmsi=235762000.

\section{CONTACT WITH THE AUTHOR}

Prof. Czesław Dymarski

Faculty of Ocean Engineering and Ship Technology,

Gdańsk University of Technology Narutowicza 11/12

80-233 Gdańsk, POLAND

e-mail: cpdymars@pg.gda.pl 